\title{
Stretching Exercises to Prevent Work-related Musculoskeletal Disorders - A Review Article
}

\author{
Qais Gasibat ${ }^{*}$, Nordin Bin Simbak, Aniza Abd Aziz \\ Faculty of Medicine, Sultan Zainal Abidin University, Gong Badak Campus, 21300 Kuala Terengganu, Malaysia \\ *Corresponding author: drqaiss9@gmail.com
}

\begin{abstract}
Background: Lower back, neck and shoulder pain, which affects the lumbar spine, are the most commonly reported Musculoskeletal Disorders (MSDs). Approximately 80 percent of the general population is affected by these disorders at a certain point during their lifetime, with some estimates being as high as 84 percent. The most commonly used approach for the treatment of MSDs is exercise therapy. Stretching provides several benefits for people at work, and may help improve morale and team cohesiveness. Another benefit of stretching is that participants may increase their range of motion compared to their counterparts who do not participate in stretching programs. Objective: The aim of this study is to synthesize the recent literature on workplace stretching exercise programs and their effects on reducing work-related MSDs in different occupational groups. Method: Specific keywords were identified and used in a systematic search to guide the discovery of relevant studies and data. Electronic databases including PubMed, ScienceDirect, and Google Scholar, were searched for the following combination of keywords: workplace, stretching, exercises, injury, work, prevention, safety, occupation, and ergonomics. Studies that do not focus on the benefits of stretching exercise were excluded simply because the present study examines prevention of work-related musculoskeletal disorders through stretching exercises. Results: Whilst majority of the literature examined in this study may not completely explain that stretching at the office will prevent work-related musculoskeletal accidental injuries, some studies have shown that performing stretching exercises can lead to reducing discomfort/pain and raising range of motion (ROM). Conclusion: Majority of the literature reviewed in this study might not fully explain that stretching at work prevents work-related musculoskeletal injuries. Some studies have shown that performing stretching exercises can contribute to reducing discomfort/pain and increasing range of motion (ROM). Particularly, construction workers who participated in stretching exercise programs reported significant positive effects including reduction in pains/disability, increase in muscle flexibility and endurance. These exercises are recommended to be performed during breaks throughout, depending on the type of occupation. All the exercises suggested could be performed at the workstation, and only require a few seconds to perform.
\end{abstract}

Keywords: stretching program, musculoskeletal disorders, workplace stretching

Cite This Article: Qais Gasibat, Nordin bin Simbak, and Aniza Abd Aziz, "Stretching Exercises to Prevent Work-related Musculoskeletal Disorders - A Review Article.” American Journal of Sports Science and Medicine, vol. 5, no. 2 (2017): 27-37. doi: 10.12691/ajssm-5-2-3.

\section{Background}

Musculoskeletal Disorders (MSDs) have become increasingly prevalent worldwide during the past decades. It is just a common cause of work-related impairment among workers with considerable financial consequences due to workers' compensation and medical expenditures [1]. Several work-related factors have been recognized to predispose the disorders. In addition, overstrained and uncomfortable back constitutes lower back pain (LBP), persistent neck and shoulder disorders, and psychological stressors for back, throat and shoulder [2]. According to the 1995 survey on self reported work-related illness in England, a person requires 13 days off work every year due to a work related upper limb disorder or neck disorder [59]. MSDs combines various inflammatory and pathological conditions affecting the muscles, muscles, ligaments, joints, peripheral nerve fibres, and supporting blood vessels. These also include clinical syndromes, such as tendons inflammations and related circumstances (tenosynovitis, epicondylitis, bursitis), lack of compression disorders (carpal canal syndrome, sciatica), and osteoarthrosis, as well as less standardised conditions such as myalgia, mid back pain and other regional pain marque not attributable to known diagnosis. Although lower extremity has recently received more attention, parts of body that are most frequently included are the lower back, throat, shoulder, forearm, and hands. MSDs are prevalent in various countries, with considerable costs and effects on quality of life. Though not uniquely caused by work, they constitute an essential proportion of most registered and/or compensable work-related diseases in various countries. Precise facts on the occurrence and frequency of MSDs are difficult to obtain, and recognized 
statistics are difficult to evaluate across countries. Nevertheless, MSDs are the single largest group of workrelated illness, representing many registered work-related diseases in the United States, the Nordic countries, and Japan [3,4,5,6]. Numerous surveys of operating populations have reported upper extremity symptom prevalences of 20 to 30 percent and even higher. In the USA, Canada, Finland, Sweden, and England, musculoskeletal disorders cause more work absenteeism or perhaps disability than any other types of disease [7-12]. MSDs occur in particular sectors and occupations with frequency rates equal to three or four times above the overall frequency. High-risk industries include nursing facilities, air flow transportation, mining, food control, leather tanning, and weighty and light manufacturing (vehicles, home furniture, appliances, electrical and digital products, textiles, apparel and shoes) [3]. Upper extremity MSDs are extremely common in manual-intensive occupations, such as clerical function, postal service, cleaning, commercial inspection and packaging [11]. Back and lower arm or leg disorders occur mostly amongst truck drivers, warehouse employees, airplane baggage handlers, building trades, nurses, nursing helps and other patient-care workers, as well as operators of cranes and other large vehicles [10].

\subsection{Types of Musculoskeletal Disorders}

The types of MSDs include upper extremity musculoskeletal disorders, back Injuries, and Lower limbs. These are explained as follows.

\subsection{Upper Extremity Musculoskeletal Disorders (UEMSDs)}

UEMSDs refer to soft tissue disorders in the neck, shoulders, arms, wrists, hands and fingers. The soft tissues include nerves, tendons, ligaments, muscle and fascia. The disorders are frequently documented as carpal tunnel syndrome, epicondylitis, neck tension syndrome, tendinitis, tenosynovitis, thoracic outlet syndrome, or white finger $[18,19,20]$. The symptoms of UEMSDs are generally characterized by pain aches, discomfort, numbness, stiffness, and/or weakness, depending on the type of disorders. UEMSDs are prevalent in jobs such as a video display terminal (VDT) operators, food processors, automobile and electronics assemblers, carpenters, garment workers, and grocery store cashiers. For example, VDT operators have often reported musculoskeletal symptoms primarily in the upper extremities, neck and shoulders [21].

Furthermore, highest occurrence rates of UEMSDs have arisen in industries where a substantial amount of repetitive, monotonous, and forceful exertion exists at work [19]. UEMSDs affect the soft tissues of the upper extremity in different ways. UEMSDs can be temporary if a rate of work vs. rest is appropriately provided. Nevertheless, they can become permanently disabling when exposures to ergonomic risk factors or poor work conditions are prolonged. Repetitive exertions, awkward posture, and mechanical pressure have been recognized as important etiological factors for chronic UEMSDs. For instance, long hours of sitting in a static posture and repetitiously keying are considered to influence the development of musculoskeletal symptoms among VDT operators [20]. In particular, the etiologic significance of psychosocial factors impacting musculoskeletal problems has been reported [21,22,23].

\subsection{Back Injuries}

Human back is the most frequently injured section of the body (22 percent of 1 several million injuries) with overexertion being the most common cause of these types of injuries [24]. Nevertheless, many back again injuries develop over a lengthy period of time by a repetitive launching of the discs caused by incorrect lifting methods or additional exertions. In fact, 27 percent of most industrial back injuries are associated with some form of lifting or perhaps manual material handling. These types of injuries are generally repetitive and result after months or perhaps years of task performance. Frequently, injuries that appear to be severe are actually the result of long-term effect. The discs of the back again vary in size, rubber-like pads filled with solid fluid, which serve as shocks. All the forces that come over the spine compress these disks, as a result of continuous and repeated squeezing. In some circumstances, devices can rupture and stick out producing pressure on the vertebral nerve resulting in back pain [24].

\subsection{Lower Limbs WMSDs}

Lower limb WMSDs are currently an issue in various occupations. They tend to become related with disorders in other parts of the body. Though the epidemiology of these WMSDs has received modest consciousness, there is appreciable proof that some activities (kneeling/squatting, rising stairs or ladders, weighty lifting, walking/standing) are essential risk factors for their advancement. Other causes for extreme lower limb WMSDs are related to slip and trip hazards [25]. Regardless of the short awareness given to this kind of WMSDs, they deserve significant concern, since they are mostly sources of high degrees of immobility and thereby can considerably reduce the quality of life [25].

\subsection{Risk Factors of WMSDs}

At least reasonable proof for causing WMSDs include heavy physical function, smoking, high body mass index, high psychosocial job demands, and the presence of comorbidities. The most commonly reported biomechanical risk factors with at least reasonable proof for causing WMSDs include extreme repetition, awkward postures, and heavy lifting. Additional large methodological quality studies are needed to further understand and provide stronger evidence of the relationship between risk elements and WMSDs [14]. The primary factors that contribute to MSDs as with most chronic illnesses have multiple risk factors; both occupational and nonoccupational. In addition to function demands, other aspects of everyday life, such as sports and household routines, may cause physical tensions to the musculoskeletal tissues. The musculoskeletal and peripheral lack of tissues are affected by systemic conditions such as rheumatoid arthritis, gout, 
and diabetes. Risk differs by age, gender, socioeconomic status, and ethnicity. Additional suspected risk factors consist of obesity, smoking, muscle power and other aspects of work capability [13].

\subsection{Cost of Occupational WMSDs}

The actual cost of occupational MSDs is usually not known. Estimates vary with respect to the method used. A traditional estimate previously published by NIOSH is $\$ 13$ billion dollars annually [14]. Other folks have estimated the cost at $\$ 20$ billion annually [16]. Regardless of the estimate utilized, the problem is large both in health insurance and economic terms. WMSDs are a major component of the frequency of work-related illness in the United States. The California Workers' Compensation Company (a nonprofit research institute) estimates that upper extremity MSDs claims by workers are averagely estimated to be $\$ 21,453$ each [17]. Back pain is by far one of the most prevalent and costly MSDs among United States sectors today. Recent analysis from the 1988 Occupational Health Supplement in the National Health Interview (an ongoing household based survey) shows that the overall prevalence of self reported back pain from repeated activities on the most recent work was 4.5 percent, or perhaps 4.75 million workers in the US [17]. The mean cost per occurrence of compensable low-back discomfort was reported to be \$8, 321 in 1989 [15].

Stretching refers to the act of performing a certain exercise to enhance joint range of motion, while versatility is traditionally considered the joint range of motion that can be measured [38]. There are three prevalent types of stretching; proprioceptive neuromuscular facilitation (PNF), stationary and isometric stretching. Proprioceptive neuromuscular facilitation stretching combines fixed and isometric stretching methods. Most advocates of extending programs recommend PNF stretching out [39]. PNF stretching out allows the muscle to become stretched to a greater level by increasing the receptor signals through a 5-10-second voluntary muscle compression followed by a 5-10-second voluntary muscle rest. With the hold-relax PNF technique, the muscle is placed right into a static stretch. The person is usually instructed to "hold" and contract the muscle against resistance from a partner intended for 10 seconds. The person can now be instructed to "relax", as well as the partner slowly moves the muscle to a new stationary position. The technique is repeated two to three times. If improperly performed, stretches may also cause or worsen injuries [40].

Stretching out programs are intended to reduce the occurrence and/or severity of accidental injuries by increasing flexibility. Versatility is commonly defined as the range of motion possible around a specific joint or series of joints, which is applied in many clinical studies. In terms of function, flexibility refers to modifications in our length of a muscle tendons unit brought about by alterations of its viscoelastic properties. Viscoelasticity is a measure of a tissue's ability to deform or modify length when a load is usually applied over time and to continue its original size and shape if the force is removed, very much like stretching and liberating a rubber band. Several laboratory researches have demonstrated that stretching leads to elongation of the muscle tendons unit, reductions in maximum force, rate of pressure production, and tensile tension on the muscle tendon device [41,42]. Therefore, stretching seems to alter the viscoelasticity from the muscle tendon unit, leading to less stiff tissues. These types of changes increase the distance the tissue can stretch and also the force required to tear the muscle tendon unit, producing injury less likely. The supposition is that, for individuals with brief or "tight" muscles, stretching out increases flexibility by lengthening the tissues to a more physiologically normal range, promoting ideal function and reducing the chance of musculoskeletal injury [41,42].

Table 1. Symptoms of different types of MSDs [25,26]

\begin{tabular}{|c|c|}
\hline Type of musculoskeletal disorders & Symptoms \\
\hline \multicolumn{2}{|l|}{ Neck and Shoulder disorders } \\
\hline Myofascial pain disorder & Discomfort and tenderness in the throat, shoulder and arm muscle mass. Painful trigger points after touch. \\
\hline Cervical spondylosis & $\begin{array}{l}\text { Intermittent/chronic neck and shoulder discomfort or stiffness, headache, hands and arm pain, tingling, } \\
\text { tingling and clumsiness. }\end{array}$ \\
\hline Thoracic outlet syndrome & Pain in shoulder, arm or hand, numbness, tingling of fingers, muscle weakness/fatigue, cold arm or hand. \\
\hline Rotator cuff tendinitis/tears & $\begin{array}{l}\text { Discomfort and stiffness in shoulder blades associated with backward and upwards arm movements. Weakness } \\
\text { of rotator cuff muscle. }\end{array}$ \\
\hline \multicolumn{2}{|l|}{$\begin{array}{l}\text { Hand and wrist disorders De } \\
\text { Quervain's disease }\end{array}$} \\
\hline Carpal tunnel syndrome & $\begin{array}{l}\text { Soreness in thumb and arm area when grasping, pinching, twisting. } \\
\text { Hand or finger numbness, pain, tingling, burning, clumpiness. Eventual muscle weakness and atrophy. } \\
\text { Symptoms often worse with increased activity. }\end{array}$ \\
\hline $\begin{array}{l}\text { Guyon's syndrome } \\
\text { Back disorders }\end{array}$ & Symptoms begin with a feeling of pins and needles in the ring and index fingers. \\
\hline Herniated spinal disk & $\begin{array}{l}\text { As well as leg numbness, tingling discomfort, weakness. Worsens with breathing problems, sneezing, sitting, } \\
\text { driving, twisting forward. }\end{array}$ \\
\hline Lower back pain & Pain, stiffness in lower spine and surrounding tissues. \\
\hline Sciatica & $\begin{array}{l}\text { Pain from lower back or hip radiating to the buttocks and legs. Leg weakness, numbness or tingling. Possible } \\
\text { causes are prolapsed intervertebral disc pressuring the sciatic nerve, worsened with prolonged sitting or } \\
\text { excessive bending/lifting. }\end{array}$ \\
\hline \multicolumn{2}{|l|}{ Lower limbs } \\
\hline Hip/thigh conditions & Osteoarthritis (most frequent), Piriformis Syndrome, Trochanteritis, Hamstring strains, Sacroiliac Joint Pain; \\
\hline Knee / lower leg & $\begin{array}{l}\text { Osteoarthritis, Bursitis, Beat Knee/Hyperkeratosis, Meniscal Lesions, Patellofemoral Pain Syndrome, Pre- } \\
\text { patellar Tendonitis, Shin Splints, Infrapatellar Tendonitis, Stress Fractures; }\end{array}$ \\
\hline Ankle/foot & $\begin{array}{l}\text { Achilles Tendonitis, Blisters, Foot Corns, Halux Valgus (Bunions), Sludge hammer Toes, Pes Traverse Planus, } \\
\text { Plantar Fasciitis, Sprained Ankle, Tension fractures, Varicose veins, Venous disorders. }\end{array}$ \\
\hline
\end{tabular}




\section{Method}

Specific keywords on work related Electronic databases including PubMed, Sciencedirect, Safety Article Archive, and Google Scholar, (from 1990 to 2017) were searched for the following keywords and combinations of these words: workplace, stretching, exercises, injury, work, prevention, safety, occupation, and ergonomics. Printed materials, including industry magazines and professional journals were also searched. Studies that do not focus on the benefits of stretching exercise were excluded simply because the present study examines prevention of workrelated musculoskeletal disorders through stretching exercises.

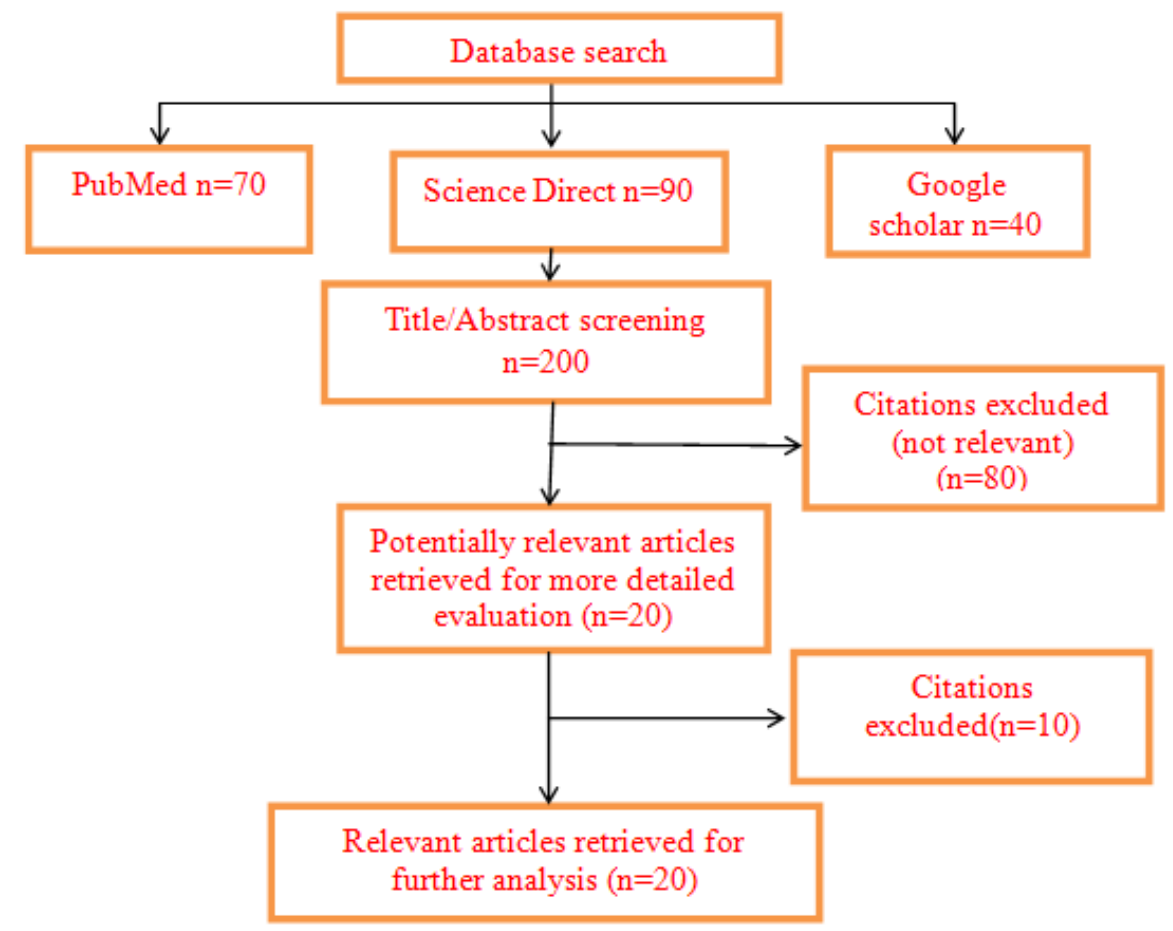

Figure 1. Illustration

\section{Result and Discussion}

Three studies that evaluated stretching programs at places of work demonstrated that this kind of exercise improves flexibility. Nevertheless, one study lacked a control group, [44] whilst two studies failed to associate improvements in flexibility with meaningful outcome measures including injury incidence or intensity $[44,45]$. Further studies are needed to define more clearly the contributions of stretching programs to injury prevention. The enhanced power demonstrated by manual managing workers who stretch is a crucial finding in the real world of workers who bend, lift up, carry, pull, and doormat many hours a day [45]. The current narrow concentrate on flexibility might be overlooking this unique aspect of stretching that could lead to reducing injuries related to employee fatigue. The reductions in injury severity and connected costs found in firefighters is surely an important aspect of stretching at the office [46]. Others explained the cost savings coming from decreasing injury severity and time loss. A review of worksite physical therapy exercise applications indicates that the greatest expenses associated with work injuries are by worker absence and time-loss compensation rather than medical care [47]. Waddell, Hess and Hecker $[43,48]$ further noted that workers with back again injuries have a reduced likelihood of returning to work if they happen to be off work for longer than six weeks. All those off work for longer than six months have less than a 50-percent chance of ever returning to effective employment, and for those in whose disability lasts longer than a 12 months, the likelihood drops to 25 percent. In this regard, minimizing time loss and damage severity is meaningful to workers and employers being injury prevention. If decreased severity is indeed a product of stretching programs, this may perhaps be as important a result as decrease of injury occurrence [43].

Studies on industry based stretching programs to mitigate Work-related Musculoskeletal Disorders (WMSDs) are discussed in the following: stretches in computer work, heavy work being the the most common complaints. Function extensive use of computers boosts the risk of developing several types of symptoms, including musculoskeletal discomfort, exhaustion, eyestrain, and mood disruptions [49,50,51,52]. Growing concerns over disabling upper-extremity injuries coming from computer intensive work have been well-publicized. Nevertheless, symptoms in the neck, shoulder blades, back, and eyes are more prevalent. Matias, Salvendy and Kuczek [53] referred to an 8-38 percent incidence and predicted a 40 percent probability of hand injuries in computer employees. Nainzadeh, Malantic-Lin, Alvarez and Loeser [52] reported an 80 percent prevalence of tension neck syndrome in computer (office) workers. Visible symptoms occur in 50-90 percent of computer workers [51,54]. The prevalence and severity of symptoms are significantly correlated with the amount of period spent performing computer jobs [53].

Jepsen and Thomsen [57] examined the effects of stretching on the prevention of upper limb disorders in the right arm among computer providers. They conducted a 
controlled study of 184 personal computer PC operators, within two diverse divisions that spend their particular workday at computer work stations. All participants spent at least 20 percent of their time for computer workstations. To set up a reference point, all of the subjects completed a questionnaire and a nerve examination. The stretching treatment consisted of a physiotherapist teaching stretching exercises based on neurodynamic concepts. The physiotherapist prescribed four different stretching exercises for the intervention subjects. Each of the several stretches focused on a different area of the right arm; the volar forearm flexors, the pronator muscle, the typical nerve and the radial lack of. The control group would not engage in any stretching. The experiment lasted for six consecutive months. Toward the completion of the experiment, all of the subjects took part in a follow up neurological test and a questionnaire. The end result data consisted of self reported discomfort levels and neurological results. The researchers found a substantial improvement with regard to the function of the pronator muscle. Mechanosensativity was significantly improved intended for the median nerve. They finally concluded that stretching alone could hardly be identified as a single way of preventing upper extremity disorders among people who work at computer system workstations [57]. The influence of rest breaks and stretches on symptoms and performance of data-entry workers has been examined in a jointly conducted study by researchers at the Countrywide Institute of Occupational Security and Health (NIOSH) and the Internal Revenue Service (IRS). The subjects were randomly divided into two groups. One group was instructed to perform brief flexibility exercises during breaks. The other group, which is the control group, did not perform stretching. In the group that performed the stretching, workers reported stretching during only 25 percent of the conventional breaks and 39 percent of supplementary fractures. The study found no significant effects of stretching out on discomfort or overall performance. The researchers concluded that since the study subjects had a low compliance in performing the stretching, the influence of the assessment could not be decided. They also suggested that further research on stretching and exercise compliance is necessary [58].

Herbert and Noronha [55] used meta-analysis to group the outcomes of comparable studies. The analysis contains five studies that looked into the effects of stretching on suspended onset of muscle soreness. An overall total of 77 subjects took part in the study (27 had been allocated to the stretching organizations, 20 subjects were invested in control groups, and 35 were allocated to both stretch out and control groups). The stretch times for subjects varied between 300 mere seconds and 600 seconds (five to ten minutes respectively). The results showed that stretching before and after exercise decreases muscle mass soreness within 72 hours. The authors felt that as this was so insignificant, virtually all athletes would not use stretching out to prevent muscle soreness. Herbert and Noronha [55] reviewed two studies that evaluated the influence of stretching on the risk of damage in new military employees. The first study analyzed the effect of stretching leg muscles and the risk of injury to specific leg injuries; lesions to the Achilles tendon, lateral ankle joint sprains, stress fractures towards the foot and tibia, periostitis, and anterior tibial area syndrome. The second study evaluated the effect of stretching half a dozen muscle groups in the lower branches (legs) on the risk of any kind of injuries to the lower legs. The subjects were defined as injury free of charge if they were able to go back to full duty without a sign on the following day. The aforementioned studies produced similar evaluations of risk reduction. A total of 2630 subjects participated in the two studies. The authors reported that there was a inconsistency in the sample size since military personnel allocated subjects to different platoons during the test. A total of 181 accidental injuries occurred in the two stretching organizations, and 200 injuries happened in the control group. Both studies revealed that stretching just decreased the risk of injury simply by 5 percent, which is not significant. The authors concluded that stretching prior to exercise does not prevent post-exercise muscle soreness. They also discovered little support for the idea that stretching immediately just before exercise can prevent possibly extreme or acute workplace injuries.

A study of 469 city and county firefighters evaluated the effectiveness of a flexibility program on function related injuries [56]. Specifically, researchers analyzed the incidence, cost and severity of joint accidents between groups of firefighters that stretched and groups that did not stretch. The stretching program consisted of one regularly 30-minute session during a six month period. Each extending session included twelve diverse exercises. The subjects that participated in the stretching out program were more flexible than subjects who did not participate. Throughout two years, the group of medical personnel that participated in stretching out incurred 48 injuries while the non-stretching group experienced 52 injuries. The injury types were not described. The cost of the injuries was significantly distinct between the two groups. The entire cost of injuries (medical and indemnity) for the number of subjects that stretched was $\$ 85,371$, while the expense of injuries for the subjects of nonstretchers were \$235, 131. This suggests that injuries suffered by the firefighters that took part in the workplace stretching program was less expensive than injuries incurred by non-stretchers [56].

\subsection{The Benefit of Workplace Exercises Program}

There is certainly an acceptance that currently there is little or no statistically significant empirical evidence of exercises for decreasing MSDs symptoms. Nevertheless, there is anecdotal evidence [30]. In this situation, coupled with some requests for information upon exercises that might be beneficial, the decision was made to perform this analysis, which is a review of related literature to identify reportedly potentially helpful exercise examples.

There is limited information in studies by HSE Books [29] provided to those who suffer from musculoskeletal discomfort during repeated or static utilization of upper limbs [29]. HSE books [29] advised that taking breaks is helpful, but there is no additional information on what employees can carry out during these breaks to maximise the advantages in terms of reducing musculoskeletal pain. Therefore, there is need to explore this area and identify exercises that are reported to be beneficial to society. 
A study conducted by Fenety and Walker [27] determined the impact of regular workout at a workstation upon musculoskeletal discomfort among workers. The subjects of the study reported an immediate reduction of musculoskeletal pain. This result exactly supports that of Henning, Jacques, Sullivan and Alteras-Webb [31], where it was determined that brief rest breaks combined with workout were more effective than unaggressive rest breaks for personally computer workers. This indicates that active recovery is more effective in reducing musculoskeletal discomfort than passive recovery. The aforementioned studies [31] did not specify the kinds of exercises used and whether stretching was included.

The research found that supplementary fractures that were intended to include extending breaks reliably minimized pain and eyestrain without impairing productivity. Low compliance in performing stretches prevented a legitimate assessment of stretching results [28]. Another study looked into the effect of exercise at the office (targeting neck, shoulders as well as the upper back) on seventy-two computer operators over a period of four weeks. They concluded that most topics found the resistance plus the stretching exercises easy to do, performed all of them 1 to 2 times daily and said they reduced distress. Kietrys, Galper and Verno [32] likewise recommend further research to examine the optimal type and rate of recurrence of at-work exercise [32].

Another study conducted by Lock and Colford [30] clearly a analyzed international literature regarding the benefits of limbering up exercise at work, including the benefits of reducing symptoms of musculoskeletal discomfort. Limbering up is known as moderate exercises, which may consist of warming up and/or stretching performed every day and regularly throughout the day. The study concluded that there was not enough proof to recommend health and fitness programs, and that there was also insufficient evidence to recommend limbering up programmes to companies. This is because the evidence for the advantages of limbering up exercises had not been specific or absolutely reliable [30].

Omer, Ozcan, Karan and Ketenci [33] also carried out a study on the effectiveness of training and workout programs in the management of MSDs. They trained the participants in mobilisation, stretching out, strengthening exercises, and found that these exercises decreased reported experiences of MSDs pain and level of depression within participants in the short term. The methods used by companies to reduce the occurrence of WMSDs and injuries are stretching and adaptability exercise programs [36]. There is a developing interest in stretching exercises to reduce the dangers of WMSDs and injuries at office. Presently, very little is known regarding the industry-specific outcomes of stretching programs.

\subsection{Criteria for an Effective Workplace Stretching Program}

Stretching is a form of physical activity in which a specific skeletal muscle mass is deliberately elongated to its fullest length to be able to improve the muscle's felt flexibility. Benefits of stretching may include improved flexibility, improved range of motion inside joints, improved circulation, increased posture, and stress relief. It is generally believed that stretching prior to or after physical activity can decrease the chance of a strain or twist injury by increasing the flexibleness of muscles, tendons and ligaments, which in turn increases the mobility in a joint or number of joints. Advocates of place of work stretching programs claim that these types of programs have reduced and prevented sprain and stress injuries. While these reviews are frequently published in journals, they are typically depending on uncontrolled and quasi-experimental in house evaluations that rely on self-reported outcomes rather than objective methods [37].

According to Hess and Hecker [43], the following are considered the criteria for an effective stretching program at workplace.

a) Warm-up for five minutes prior to stretching.

b) Exercises should be tailored to commonly performed job duties.

c) Stretch regularly: a minimum of two-three days/week.

d) Perform stretches correctly.

e) Hold stretch 15-30 seconds.

f) Two-three repetitions per muscle group.

A person can use a band or towel, which is helpful in moving the hand while performing the exercises. Moreover, a suitable exercise can be chosen depending on the person's occupation. The following Table 2 summarizes the commonly performed exercises, which are also mostly recommended [60-67].

Table 2. Upper limb stretching exercises

\begin{tabular}{ll}
\hline Name of exercise & Description \\
Eyes & $\begin{array}{l}\text { Sit up straight, face forward and repeat this sequence several times } \\
\text { without moving the head. Look up, then down. Look left, then right. }\end{array}$ \\
Neck stretches retraction & $\begin{array}{l}\text { Pull head back as far possible and down slightly. Hold posture for } 10- \\
15 \text { seconds. Return your head to the centre Repeat } 2 \text { or } 3 \text { times. }\end{array}$ \\
Rotate Head From Side To Side & $\begin{array}{l}\text { Slowly turn your head left as far as you can. Hold posture for } 10-15 \\
\text { opposite direction and hold for } 10-15 \text { seconds. Repeat } 2 \text { or } 3 \text { times. }\end{array}$ \\
Tilt head From Front To Back & $\begin{array}{l}\text { Tilt your head slowly back, far enough so you can look up. Hold } \\
\text { posture for } 10-15 \text { seconds. Return slowly to a normal position, then tilt } \\
\text { forward to stretch the back of your neck and hold for } 10-15 \text { seconds. } \\
\text { Repeat } 2 \text { or } 3 \text { times. }\end{array}$
\end{tabular}




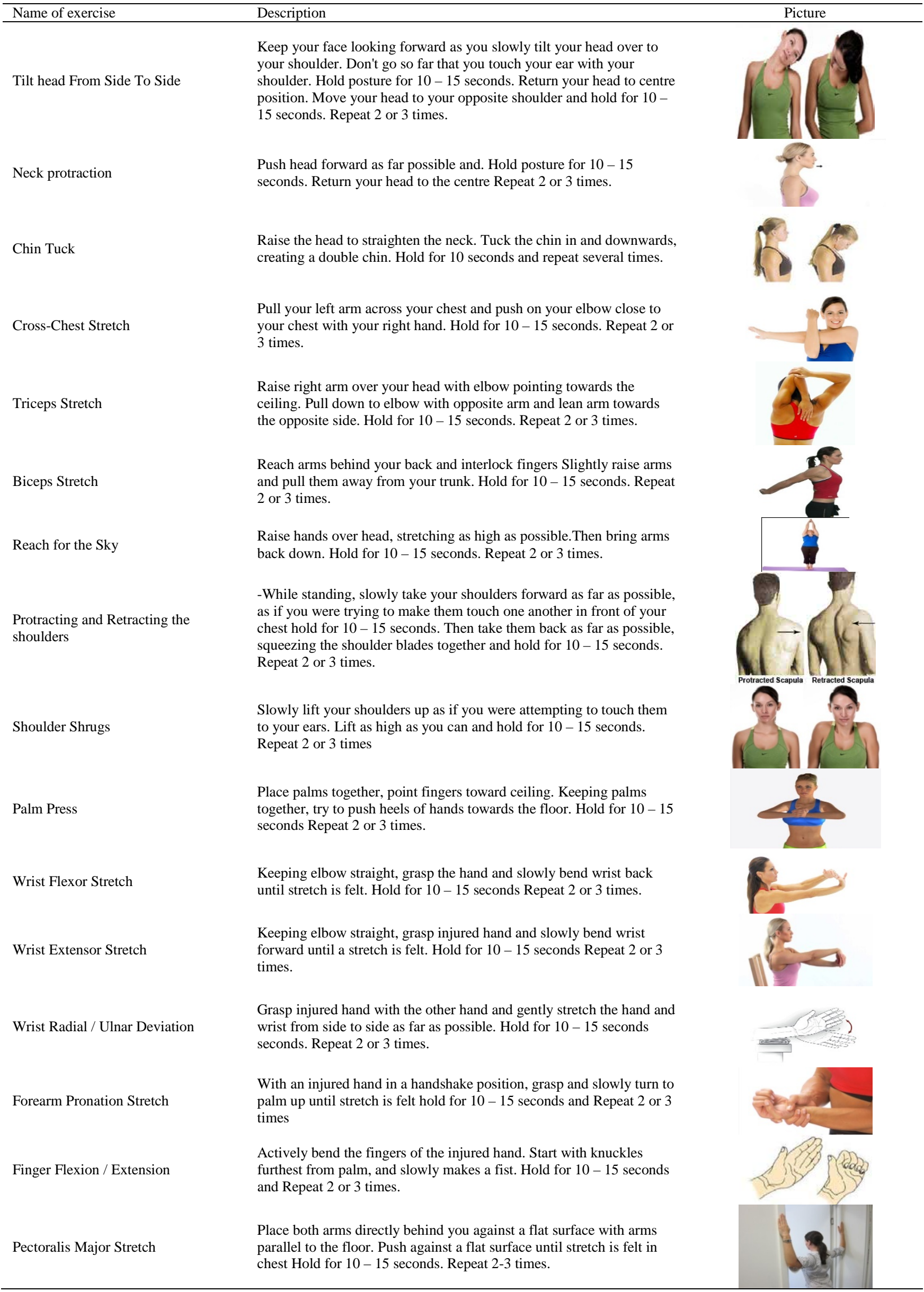




\begin{tabular}{ll}
\hline Name of exercise & Description \\
Lying Abdominal Stretch & $\begin{array}{l}\text { Lie on front side and push upper torso upwards with arms until stretch } \\
\text { is felt. Hold for } 10-15 \text { seconds Repeat } 2-3 \text { times. }\end{array}$ \\
Side stretching & $\begin{array}{l}\text { From a neutral standing position slowly bend to the left or right Hold } \\
\text { for } 10-15 \text { seconds Repeat 2-3 times. }\end{array}$ \\
Oblique muscle stretch & $\begin{array}{l}\text { Feep your back straight and slowly rotate your shoulders to each side. } \\
\text { Repeat } 10-15 \text { times. }\end{array}$ \\
\hline
\end{tabular}

Table 3. Back stretching exercises

Name of exercises
Cat and Camel
On all fours, assume a "hump" back position by arching the backup.
Hold briefly and then slowly lower the back into a sagging position
Tail Wag

Table 4. Lower limb stretching exercises

\begin{tabular}{|c|c|c|}
\hline Name of exercise & Description & Pictures \\
\hline Standing Quadriceps Stretch & $\begin{array}{l}\text { Pull heel toward buttocks until a stretch is felt in front of the thigh. Keep } \\
\text { leg close to body with knee pointing to the floor. Hold for } 10-15 \\
\text { seconds Repeat } 2-3 \text { times. }\end{array}$ & \\
\hline Lying Quadriceps Stretch & $\begin{array}{l}\text { Lie on your side. Pull heel toward buttocks until a stretch is felt in front } \\
\text { of the thigh Hold for } 10-15 \text { seconds Repeat } 2-3 \text { times. }\end{array}$ & \\
\hline Lying Hamstring Stretch & $\begin{array}{l}\text { Slowly bring the knee towards the chest. Gently extend leg with knee } \\
\text { slightly bent and hold when in a comfortable stretch. Hold for } 10-15 \\
\text { seconds Repeat 2-3 times. }\end{array}$ & \\
\hline Sitting Hamstring Stretch & $\begin{array}{l}\text { Bend knee of left leg and keep right leg extended with the knee slightly } \\
\text { bent. Bend at the waist towards your left foot. Hold your lower leg for } \\
\text { support. Hold for } 10-15 \text { seconds Repeat 2-3 times. }\end{array}$ & \\
\hline Standing Hamstring Stretch & $\begin{array}{l}\text { Left leg in front of you. Bend right knee. Lean forward, placing hands on } \\
\text { bent leg. Keep back straight. Hold for } 10-15 \text { seconds Repeat } 2-3 \text { times. }\end{array}$ & \\
\hline Soleus (Lower calf) & $\begin{array}{l}\text { Hands against the wall. Keep the back leg straight, bend knees of both } \\
\text { legs. Push heels down and slowly lean forward until a stretch is felt in the } \\
\text { back of the calf Hold for } 10-15 \text { seconds Repeat } 2-3 \text { times. }\end{array}$ & \\
\hline Gastrocnemius (Upper calf) & $\begin{array}{l}\text { Hands against the wall. Keep back leg straight Push heels down and } \\
\text { slowly lean forward until a stretch is felt in the back of the calf Hold for } \\
10-15 \text { seconds Repeat } 2-3 \text { times. }\end{array}$ & \\
\hline Hip Adductors stretching & $\begin{array}{l}\text { Gently push knees to floor until a stretch is felt. Keep back straight. Hold } \\
\text { for } 10-15 \text { seconds Repeat } 2-3 \text { times. }\end{array}$ & \\
\hline Hip Abductors stretching & $\begin{array}{l}\text { Cross your right leg over your left leg. Look over your right shoulder } \\
\text { while turning your trunk and pushing back on knee with left elbow Hold } \\
\text { for } 10-15 \text { seconds Repeat } 2-3 \text { times. }\end{array}$ & \\
\hline
\end{tabular}




\begin{tabular}{|c|c|c|}
\hline Name of exercise & Description & Pictures \\
\hline Hip Flexors/Extensors & $\begin{array}{l}\text { Slowly lean and push hip to floor until a stretch is felt in front of hip Hold } \\
\text { for } 10-15 \text { seconds Repeat } 2-3 \text { times }\end{array}$ & \\
\hline Gluteal Muscles stretching & $\begin{array}{l}\text { Place right foot above left knee. Slowly lift left leg towards the chest. } \\
\text { Keep arms flat on floor Hold for } 10-15 \text { seconds Repeat 2-3 times. }\end{array}$ & \\
\hline Anterior Tibialis Stretch & $\begin{array}{l}\text { Sit in a chair and cross your right leg onto your left thigh. Your } \\
\text { malleolus, or 'ankle bone', should be about } 2 \text { inches off your thigh. With } \\
\text { your left hand, grasp the top of your foot and pull your foot towards your } \\
\text { left side, making sure movement occurs at the ankle joint. A stretch } \\
\text { should NEVER HURT! Attain a good, pain free stretch and hold for } 15 \\
\text { seconds, then switch and stretch left leg,. Repeat that 2-3 times. }\end{array}$ & \\
\hline Plantar flexion stretches & $\begin{array}{l}\text { Point the foot down against resistance of the tubing. Let up slowly Repeat } \\
2-3 \text { times. }\end{array}$ & \\
\hline Dorsiflexion stretches & $\begin{array}{l}\text { Pull the foot towards the face against the resistance of the tubing. Lower } \\
\text { slowly Hold for Repeat 2-3 times. }\end{array}$ & \\
\hline Inversion stretches & $\begin{array}{l}\text { Turn the sole of the foot inward against resistance of the tubing. Let out } \\
\text { slowly. Keep knee pointed up. Repeat 2-3 times. }\end{array}$ & \\
\hline Eversion stretches & $\begin{array}{l}\text { Turn the sole of the foot outward against resistance of the tubing. Let in } \\
\text { slowly. Keep knee pointed up. Repeat 2-3 times. }\end{array}$ & \\
\hline Seated Calf Stretch & $\begin{array}{l}\text { In a sitting position, loop a towel around the ball of your foot. Gently pull } \\
\text { back on the towel. The knee should be straight. Hold for } 10-15 \text { seconds } \\
\text { Repeat } 2-3 \text { times. }\end{array}$ & \\
\hline
\end{tabular}

\section{Conclusion}

This study explored the latest research literature on place of work stretching exercise programs and their influence on reducing work-related MSDs in various occupational groups. While this study supports that stretching improves flexibility/ROM and personal value, stretching alone may not prevent work-related musculoskeletal disorders and injuries. Some studies also suggested that weight training, conditioning, and warm-up play an important role in preventing work-related MSDs. It should be noted that work-related MSDs are costly to organizations, and also cause employee working errors that result in low quality of work and decreased operational productivity. Overall, the present study illustrated a few favorable outcomes of stretching exercise programs in several occupations, but it is controversial to accomplish a definite response about the exploitation of stretching in preventing work-related musculoskeletal disorders and accidental injuries.

\section{Acknowledgements}

The authors express stupendous gratitude to the Libyan Ministry of Education for awarding scholarship to Qias Gasibat, and appreciate the effort of Sultan Zainal Abidin Universiti, Malaysia for providing the necessary facilities to conduct this study.

\section{References}

[1] Andersson, G. B. "Epidemiological features of chronic low-back pain”. The lancet, 354 (1999): 581-585.

[2] Szymanska, J. "Disorders of the musculoskeletal system among dentists from the aspect of ergonomics and prophylaxis”. Annals of Agricultural and Environmental Medicine, 9 no. 2 (2002): 169-173.
[3] Punnett, L., \& Wegman, D. H. "Work-related musculoskeletal disorders: the epidemiologic evidence and the debate”. Journal of electromyography and kinesiology, 14 no.1 (2004): 13-23.

[4] National Research Council. Musculoskeletal disorders and the workplace: low back and upper extremities. National Academies Press, 2001.

[5] M.H. Pope, G.B.J. Andersson, J.W. Frymoyer, D.B. Chaffin (Eds.), Mosby-Year Book, Inc, St Louis, MO, 1991.

[6] G. Sjøgaard, O.M. Sejersted, J. Winkel, J. Smolander, K. Westgaard, R.H. Westgaard. "Exposure assessment and mechanisms of pathogenesis in work-related musculoskeletal disorders: significant aspects in the documentation of risk factors”, in: O. Johansen, C. Johansen (Eds.), Work and health: Scientific basis of progress in the working environment; February 22-25, 1993. European Commission, Directorate-General V, Employment, Industrial Relations and Social Affairs, Copenhagen, Denmark, (1993): 75-87.

[7] E.M. Badley, I. Rasooly, G.K. Webster. "Relative importance of musculoskeletal disorders as a cause of chronic health problems, disability, and health care utilization: Findings from the 1990 Ontario Health Survey”. The Journal of Rheumatology, 21 no. 3 (1994): 505-514.

[8] A. Feeney, F. North, J. Head, R. Canner, M. "Marmot, Socioeconomic and sex differentials in reason for sickness absence from the Whitehall II study". Occupational and Environmental Medicine, 55.2 (1998): 91-98.

[9] M. Leijon, G. Hensing, K. Alexanderson. "Gender trends in sicklisting with musculoskeletal symptoms in a Swedish county during a period of rapid increase in sickness absence”. Scandinavian Journal of Social Medicine, 26.3 (1998): 204-213.

[10] M.H. Pope, G.B.J. Andersson, J.W. Frymoyer, D.B. Chaffin (Eds.), Mosby-Year Book, Inc, St Louis, MO, 1991.

[11] D.M. Rempel, L. Punnett. "Epidemiology of wrist and hand disorders”, in: M. Nordin, G.B. Andersson, M.H. Pope (Eds.), Mosby-Year Book, Inc, Philadelphia, PA, 1997, pp. 421-430.

[12] H. Riihima"ki. "Editorial: Hands up or back to work-future challenges in epidemiologic research on musculoskeletal diseases". Scandinavian Journal of Work Environment and Health, 21 (1995): 401-403.

[13] WHO. Identification and control of work related diseases. Technical Report Series no. 714, World Health Organisation, Geneva, Switzerland, 1985.

[14] NIOSH. National occupational research agenda. Cincinnati, $\mathrm{OH}$ : U.S. Department of Health and Human Services, Public Health Service, Centers for Disease Control and Prevention, National Institute for Occupational Safety and Health, DHHS (NIOSH) Publication, 1996, pp. 96-115. 
[15] Webster BS, Snook SH. "The cost of compensable upper extremity cumulative trauma disorders”. J Occup Med 36 no. 7 (1994): 713-727.

[16] AFL-CIO. Stop the pain. Washing-ton, 1997, DC: AFL-CIO.

[17] CWCI. Report on CTDs. San Francisco, CA: California Workers' Compensation Institute, 1993.

[18] Bongers, P. M., Kremer, A. M., \& Laak, J. T. “Are psychosocial factors, risk factors for symptoms and signs of the shoulder, elbow, or hand/wrist?": A review of the epidemiological literature. American journal of industrial medicine, 41no. 5 (2002): 315-342.

[19] DiNardi, S. R. The occupational environment: its evaluation, control, and management (Vol. 111). Fairfax, VA: AIHA Press, 2003, pp. 18-27.

[20] Lundberg, U. "Psychophysiology of work: Stress, gender, endocrine response, and work - related upper extremity disorders". American journal of industrial medicine, 41 no. 5 (2002): 383-392.

[21] Faucett, J., \& Rempel, D. "VDT - related musculoskeletal symptoms: Interactions between work posture and psychosocial work factors”. American journal of industrial medicine, 26 no. 5 (1994): 597-612.

[22] Park, J. K., Kim, D. S., \& Seo, K. B. "Musculoskeletal disorder symptom features and control strategies in hospital workers". Journal of the Ergonomics Society of Korea, 27 no. (2008): 3. 81-92.

[23] Östergren, P. O., Hanson, B. S., Balogh, I., Ektor-Andersen, J., Isacsson, A., Örbaek, P., ... \& Isacsson, S. O. "Incidence of shoulder and neck pain in a working population: effect modification between mechanical and psychosocial exposures at work? Results from a one year follow up of the Malmö shoulder and neck study cohort”. Journal of epidemiology and community health, 59 no. 9 (2005): 721-728.

[24] McCauley-Bush, P. Ergonomics: foundational principles, applications, and technologies. CRC Press, 2011.

[25] Nunes, I. L., \& Bush, P. M. (2012). Work-related musculoskeletal disorders assessment and prevention. INTECH Open Access Publisher.

[26] Mathew, S. T. "Posturedontics in dentistry: A review. Journal of Dentistry and Oral Hygiene, 7 no. 6 (2015): 78-85.

[27] Fenety A, Walker JM. "Short-term effects of workstation exercises on musculoskeletal discomfort and postural changes in seated video display unit workers”. Phys Ther 82 (2002): 578-589.

[28] Galinsky T, Swanson N, Sauter S, Dunkin R, Hurrell J, Schleifer L. "Supplementary breaks and stretching exercises for data entry operators: a follow-up field study”. American journal of industrial medicine 50 (2007): 519-527.

[29] HSE Books; L26 Work with Display Screen Equipment; ISBN 0717625826 .

[30] Lock D, Colford N. International review of the literature relating to the benefits of limbering up exercises at work. HSE Research Report 309 (2005).

[31] Henning RA, Jacques P, Kissel GV, Sullivan AB, Alteras-Webb SM. "Frequent short rest breaks from computer work: Effects on productivity and well-being at two field sites”. Ergonomics, 37 (1997): 1697-1707.

[32] Kietrys, D. M., Galper, J. S., \& Verno, V. "Effects of at-work exercises on computer operators”. Work, 28 no.1 (2007): 67-75.

[33] Omer S E, Ozcan E, Karan A, Ketenci A. "Musculoskeletal system disorders in computer users: Effectiveness of training and exercise programs". Journal of backs and musculoskeletal rehabilitation, 17 (2004): 9-13.

[34] Miranda H, Viikari-Juntura E, Martikainen R, Takala E-P, Riihimaki H. "A prospective study of work related factors and physical exercise as predictors of shoulder pain”. Occup Envirin Med, 58 (2001): 528-534.

[35] Griffin, L., Leite, F., Machemehl, R., Fleisher, T., \& Choe, S. Stretch and Flex Program for TxDOT Office and Field Workers, No. FHWA/TX-14/0-6805-1, 2014.

[36] Drennan, F. S., Ramsay, J. D., \& Richey, D. "Program Development-Integrating Employee Safety \& Fitness: A Model for Meeting NIOSH's Steps to a Healthier US Workforce Challenge-An aging workforce has become a key driver of high workers”. Professional Safety, 51 no.1 (2006): 26-35.

[37] Hess, J. A., \& Hecker, S. "Stretching at work for injury prevention: issues, evidence, and recommendations”. Applied occupational and environmental hygiene, 18 no. 5 (2003): 331-338.
[38] Magnusson, P., \& Renström, P. “The European College of Sports Sciences Position statement: The role of stretching exercises in sports”. European journal of sport science, 6 no. 2 (2006): 87-91.

[39] Sharman, M. J., Cresswell, A. G., \& Riek, S. "Proprioceptive neuromuscular facilitation stretching”. Sports Medicine, 36 no. 11 (2006): 929-939.

[40] da Costa, B. R., \& Vieira, E. R. "Stretching to reduce work-related musculoskeletal disorders: A systematic review”. Journal of Rehabilitation medicine, 40 no. 5 (2008): 321-328.

[41] Taylor, D.C.; Dalton, J.D.; Seaber, A.V. "Viscoelastic Properties of MuscleTendon Units: The Biomechanical Effects of Stretching”. Am J Sport Med, 18 no. 3 (1990): 300-309.

[42] Magnusson, S.P.; Simonsen, E.B.; Aagaard, P. "Biomechanical Responses to Repeated Stretches in Human Skeletal Muscle”. In Vivo. Am J Sport Med, 24 no. 5 (1996): 622-628.

[43] Hess, J. A., \& Hecker, S. "Stretching at work for injury prevention: issues, evidence, and recommendations”. Applied Occupational and Environmental Hygiene, 18 no. 5 (2003): 331-338.

[44] Moore, T.M. A Workplace Stretching Program. AAOHN J, 46 no. 12 (1998): 563-568.

[45] Genaidy, A.; Delgado, E.; Garcia, S. "Effects of a Job-Simulated Exercise Programme on Employees Performing Manual Handling Operations”. Ergonomics, 37 no 1 (1994): 95-106.

[46] Hilyer, J.C.; Brown, K.C.; Sirles, A.T. “A Flexibility Intervention to Reduce the Incidence and Severity of Joint Injuries Among Municipal Fire- fighters”. J Occup Med, 32 no. 7 (1990): 631-637.

[47] Hochanadel, C.D.; Conrad, D.E. "Evolution of an On-Site Industrial Physical Therapy Program”. J Occup Med, 35 no. 10 (1993): 1011-1016.

[48] Waddell, G. "Volvo Award in Clinical Sciences". A New Clinical Model for the Treatment of Low Back Pain, Spine, 12 no. 7 (1987): 632-644.

[49] Carter JB, Banister EW. "Musculoskeletal problems in VDTwork: A review”. Ergonomics, 37 (1994): 1623-1648.

[50] Schleifer LM, Galinsky TL, Pan CS. "Mood disturbances and musculoskeletal discomfort: Effects of electronic performance monitoring under different levels of VDT data-entry performance". Int J Hum Comput Interact, no. 8 (1996): 369-384.

[51] Anshel J. 1998. "Visual ergonomics in the workplace. London: Taylor \& Francis.

[52] Nainzadeh N, Malantic-Lin A, Alvarez M, Loeser, A. "Repetitive strain injury (cumulative trauma disorder): Causes and treatment”. Mt Sinai J Med, no. 66 (1999): 192-196.

[53] Matias A, Salvendy G, Kuczek T. "Predictive models of carpal tunnel syndrome causation among VDT operators". Ergonomics, no. 41 (1998): 213-226.

[54] Lim S-Y, Sauter SL, Schnorr TM. Occupational health aspects of work with video display terminals. In: Rom WN, editor. Environmental and occupational medicine, 3rd edition. Philadelphia: Lippincott-Raven, (1998), pp. 1333-1344.

[55] Herbert, R. D., \& de Noronha, M. Stretching to prevent or reduce muscle soreness after exercise. The Cochrane Library, (2007).

[56] Hilyer, J. C., Brown, K. C., Sirles, A. T., \& Peoples, L. “A flexibility intervention to reduce the incidence and severity of joint injuries among municipal firefighters". Journal of Occupational and Environmental Medicine, 32 no. 7 (1990): 631-637.

[57] Jepsen, J. R., \& Thomsen, G. "Prevention of upper limb symptoms and signs of nerve afflictions in computer operators: the effect of intervention by stretching”. Journal of Occupational Medicine and Toxicology, 3 no. 1 (2008): 1.

[58] Galinsky, T., Swanson, N., Sauter, S., Dunkin, R., Hurrell, J., \& Schleifer, L. "Supplementary breaks and stretching exercises for data entry operators: A follow-up field study”. American journal of industrial medicine, 50 no. 7 (2007): 519-527.

[59] Information sheet 2/99/EMSU Economic Impact: Revised data from Self Reported Work Related Illness survey in 1995 (SWI95) available at: http://www.hse.gov.uk/statistics/books.htm\#swi.

[60] Leah, C. Exercises to Reduce Musculoskeletal Discomfort for People Doing A Range of Static and Repetitive Work. Norwich, England: HSE Books, 2011.

[61] Sunley, K. Prevention of Work-Related Musculoskeletal Disorders In Sonography. London: Society of Radiographers, (2006).

[62] Griffin, Lisa, et al. Stretch and Flex Program for TxDOT Office and Field Workers. No. FHWA/TX-14/0-6805-1, 2014. 
[63] Kumar, D. K., Rathan, N., Mohan, S., Begum, M., Prasad, B., \& Prasad, E. R. "Exercise prescriptions to prevent musculoskeletal disorders in dentists”. J Clin Diagn Res, 8 no. 7 (2014): 13-16.

[64] Risk Control Bulletin Stretching \& Flexing to Reduce the Risk of Work-Related Disorders (MSDs).

[65] Marangoni, A. H. "Effects of intermittent stretching exercises at work on musculoskeletal pain associated with the use of a personal computer and the influence of media on outcomes". Work, 36 no. 1 (2010): 27-37.

[66] Mathew, Shibu Thomas. "Posturedontics in dentistry: A review". Journal of Dentistry and Oral Hygiene 7 no. 6 (2015): 78-85.
[67] Siler, B. The Pilates Body: The Ultimate at Home Guide to Strengthening, Lengthening, and Toning Your Body-without, (2000).

[68] Thacker, Stephen B., et al. "The impact of stretching on sports injury risk: a systematic review of the literature." Medicine \& Science in Sports \& Exercise36.3 (2004): 371-378.

[69] Graves, Rod J., et al. "Development of risk filter and risk assessment worksheets for HSE guidance-'Upper Limb Disorders in the Workplace'2002." Applied Ergonomics 35.5 (2004): 475-484.

[70] Choi, Sang D., and Todd Woletz. "Do stretching programs prevent work-related musculoskeletal disorders." Journal of Safety, Health and Environmental Research 6.3 (2010): 1-19. 